\title{
THE ROLE OF SOCIAL MEDIA IN GASTRONOMY INDUSTRY
}

\author{
Éva Görgényi Hegyes ${ }^{1}$ - Balázs Máté ${ }^{2}$ - Seyyed Amir Vafaei ${ }^{3}$ - Mária Fekete Farkas ${ }^{4}$ \\ ${ }^{1}$ Szent István University, Hungary H-2100 Gödöllő, Páter K. u. 1., eva.hegyesne.gorgenyi@phd.uni-szie.hu \\ ${ }^{2}$ Szent István University \\ ${ }^{3}$ Szent István University, S.A.Vafaei@gmail.com \\ ${ }^{4}$ Szent István University, farkasne.fekete.maria@gtk.szie.hu
}

\begin{abstract}
Considering the rapidly changing business environment, staying competitive is a key issue and challenge for companies in the 21st century. The criteria of a company's success and competitiveness is the changing behavior of the different economic actors and its influence. Through the information society came to the fore, the use of diverse information technology tools and methods has become a significant influence factor in terms of the entrepreneurs or company management and also the customers or other partners. Due to the rapid expansion of new technology developments, the role and importance of social media is continuously increasing. Also statistics show that one of the most regularly used IT tool is the social media and the different web 2.0 applications.

The current study is intended to provide a better understanding how social media can emphasize the competitiveness of companies and format the consumer behavior in a special sector - the rapidly developing gastronomy industry. This paper presents an empirical research about the role of social media in the above mentioned industry based on the primary data which are gathered through a survey performed in Hungary. Beyond the empirical results presented, the paper also aims to provide some recommendations for research methodology - based on the international literature review and the Authors' own experiences - both in gastronomy industry's and customers' point of view. Through the analysis the research hypotheses were examined and the most important correlations were identified between the survey results and the Authors' initial supposition.
\end{abstract}

Keywords: social media, gastronomy, consumer behavior, marketing strategy, communication. (JEL Code: D83, L83, M31, Z33)

\section{INTRODUCTION}

Due to the rapid expansion of different technology innovations, also marketing rules and activities have radically changed in the last few decades. Furthermore, organizations have been affected or influenced by the global recession and financial crisis not only in Hungary, but all over the world. Firms had to find new tactics, strategies and solutions because of these new challenges regardless of industry. While they are developing new strategies and trying to understand better their customers' changing behaviors and attitudes, they become to use new solutions offered by the continuously developing information and communication technology. Recently, one of the most conspicuous tools which organizations have used to achieve their goals and reach their target audience is social media, with its all means (KIRTIS and KARAHAN 2011). This type of mobile communication enables individuals to move and generate, transmit, receive and share different kinds of information and interact with each other regardless of financial resources, time and location (ŽIVKOVIĆ et al. 2014). "Due to its particularly cost reducing effects, it's considered that it has become the most preferred marketing driver among business environment under economic turmoil" (KIRTIS and KARAHAN 2011).
As stated in Internet World Stats data (2017), the number of internet users is continuously increasing globally year by year - nowadays more than the half of total population (more than 3.6 billion people) uses Internet in the world. The tendency represents a significant and impressive growth (918\%) between 2000 and 2016. While the world's biggest social networking site, Facebook has got over 1.6 billion users globally (1.23 billion daily active users on average), on the most famous microblogging site Twitter, there are 313 million active users (who log in at least once a month) and 500 million tweets per day. At the same time, on the video sharing site YouTube, more than 6 billion hours of video are watched every month, and there are over 1 billion monthly active users (SOCIALBAKERS, 2017).

The existence and wide availability of the Internet have fundamentally changed the way how consumers search and access information, or share their own experiences with others through feedbacks. Businesses are focusing on the opportunities offered by information technology in order to get new markets. Currently social media applications are used to analyze, monitor and talk to customers in real time regardless of location. These tools can provide an environment that allows the study and analysis of massive marketing data, 
sales strategy, advertising campaign, and the direct dealing with the client. The effective marketing communications do not lie in what you say, but how you say it, considering the marketing channels and creativity of the message. Through social networks, companies have developed new markets and increased existing ones since social networks allow them to interact with existing and potential clients and to address in a faster way the comments, suggestions and doubts they have (RODRÍGUEZ et al. 2015).

Nowadays use of social media has become a crucial factor in the daily life of both organizations and individuals, especially in service economy. This trend can be observed also in case of gastronomy industry as part of tourism use of social media applications is especially important for tourism in service sector, which is information-intensive activity. According to LOVELOCK and WIRTZ (2007), "the size of the service sector is increasing around the world, in both developed and emerging countries". Building successful service-based brand in tourism means that each offer should be a unique value proposition based on the customer experience. Online marketing communication tools are significant components of the tourists' decision-making process and enables them to participate in the co-creation of their own experiences, thus creating and adding value to their visit (BUHALIS and LAW 2008; NEUHOFER et al., 2013). However, according to UNWTO (2012) only a small number of the food tourism organizations such as restaurants engaged with tools and applications offered by digital world such as blogs or social networks. Numerous studies demonstrated that online engagement contributes to consumer loyalty, increased satisfaction, trust, commitment, word of mouth and value cocreation therefore this area should be improved in the future (VIVEK et al. 2012; SO et al. 2012).

The current situation of tourism, especially in gastronomy requires from restaurants to exploit more effectively these new communication channels. The circumstances of restaurants in Hungary are very difficult because of the recession - the number of local guests rapidly and significantly decreased while the number of well-known and high quality restaurants is continuously increasing. The highest rate of population who never goes to restaurant is in Hungary (17\%), and only $28 \%$ of the total population goes there at least once annually (compared with 68-78\% in France) (BARNÓTH, 2014). Therefore, also restaurants have to use other communication channels and count other sources such as culinary tourism or gastro-tourism as a form of tourism which has been created by the changing consumption habits. In order to influence also the local guests' restaurant choosing habits and behaviors, restaurants need to modify their communication and marketing strategy through providing continuously updated and reliable information with use of different social media applications. Furthermore, after the recession it is crucial to examine the different communication tools in order to reach the guests effectively.

Although using social media is getting popular day by day (STATISTA, 2018), there is still lack of information about different usage of social media in different scopes and zones. The current paper is intended to summarize the most important literature in terms of social media and gastronomy industry. The main objective is to find the role of social media in the restaurant choosing habits of guests - how the social media applications can influence the consumer behavior and decision making process.

\section{LITERATURE REVIEW \\ Social media definition and classification}

Nowadays social media plays a crucial role in online communication, especially in life of the Generation Y's or Digital Natives (born after 1981) (BOLTON et al. 2013). To understand the definition of social media it is essential to distinguish this term from the term of web 2.0 which is a platform, spanning all connected devices. The term of social media was firstly used in 2004 to describe the new way of utilizing the World Wide Web by the software developers and end-users (KAPLAN and HAENLEIN, 2010). The most comprehensive definition was determined by O'Reilly in 2005: a platform delivering software as a continually-updated service that enables more people to use it better, consuming and remixing data from multiple sources, allows remixing by others and creating network effects through an architecture of participation (O'REILLY, 2005; EVANS, 2014, BOULOS and WHEELERT 2007). KAPLAN and HAENLEIN (2010) define social media as the group of different online applications "that build on the ideological and technological foundations of Web 2.0 and that allow the creation and exchange of User Generated Content".

The following list summarizes the most important social media channels, as the classification of social media, with a short description and provides some example platforms:

- blogs (e.g. WordPress, HealthLiveBlog): sites that contains regularly-updated, date-stamped entries, displayed in reverse chronological order;

- collaborative projects (e.g. Google Groups): online forums or discussion sites that allow certain groups of people to collaborate, work together in order to create online content;

- media sharing sites (e.g. YouTube, Flickr): contact channel that enables people to share different media content (photos, videos, clips etc.) with others;

- microblogging (e.g. Twitter, Tumblr): allow users to share small amounts of digital content - such as short sentences, video links or images. The main difference in compared with blogs is the smaller content size;

- podcasts (e.g. Podomatic): series of digital media content (audio or video) distributed in websites.

- reviews and rating sites (e.g. FourSquare, TripAdvisor, Amazon, Booking.com): websites that enable the users to share their own opinions, feedbacks related to other people, products, services etc.;

- social networking sites (e.g. Facebook, LinkedIn): online communities for information sharing, social connection and other interactions;

- virtual game and social worlds (e.g. World of War- 
craft): the group of platforms that simulate a threedimensional world in which users can interact with others in this environment (similar to real life);

- wikis (e.g. Wikipedia): websites that enable users to edit and publish easily documents (interlinking pages) using a simple language and a web browser.

- widgets/badgets/gadget buttons: small applications that can be easily shared or embedded in other sites.

(KAPLAN and HAENLEIN 2010; RYAN, 2014)

\section{IMPORTANCE OF SOCIAL MEDIA IN MARKETING STRATEGY}

In the last few decades, communication needs and habits have been drastically changed - the rapid expansion of the Internet has shifted the focus from the use of traditional media tools (such as TV, radio, newspapers etc.) to exploiting of opportunities offered by the online world (especially social media) regardless of location and industry. In this paper traditional communication methods mean the typical ATL and BTL tools - such as television, radio, newspapers, PR, DM, POS, newsletters and traditional online communication (web 1.0) - while social media or web 2.0 applications will be categorized as the new way for marketing communication. Table 1 represents the main differences between traditional media and social media:

Internet users - especially young people - prefer the online opportunities and platforms offered by the Internet against traditional media. During its 15 -year history, online social media has reached its current situation, when it has become the distributor of information, ideas and different works and has merged the functions of traditional media. Due to the fact that interactive content of social media is created by its users it seems to users a more democratic way of communication that emphasizes individuals, group affiliation and immensity of views. In addition to its main advantages, the speed is what makes it more consistent with the needs of young generation than traditional media (NMHH, 2017).

Because of the above-mentioned characteristics as advantages of the social media, it has become more and more important in marketing communication. Although KOT et al. (2016) state that the mostly used medium to find information about a product and the execution of purchase is the search engine and social networks do not have a significant effect to the customers' purchasing decisions, different web 2.0 applications can be effectively used in case of online communication campaigns. The emergence of costumerto-costumer communication has made it possible for one user (individual or organization) to share information with hundreds or thousands of other people (MANGOLD and FAULDS 2009). Hence, the appearance and spread of social media has made it necessary to rethink the original marketing promotional mix. MANGOLD and FAULDS (2009) created a new paradigm presents the power and impact of discussions and consumer using social media - showed by Figure 1. Nowadays there are some relevant trends that are representing in this new paradigm. One of the most important facts is that Internet has become a mass media opportunity - consumers use Internet for searching and sharing information, contacting with each other, reviewing the feedback of other people, etc.

Table 1 Differences between traditional media and social media

\begin{tabular}{|c|c|c|}
\hline $\begin{array}{c}\text { Communication } \\
\text { form }\end{array}$ & Traditional media & Social media \\
\hline Interactivity & $\begin{array}{l}\text { - One-way (one-to-many) communication / } \\
\text { monologue; } \\
\text { - } \quad \text { Connectivity - only informing the users; } \\
\text { - } \quad \text { Sess opportunity for misinformation; } \\
\text { - } \quad \text { Only search and browse. }\end{array}$ & $\begin{array}{l}\text { Many-way (many-to-many) } \\
\text { communication / dialogue; } \\
\text { - Interactivity - engaging the audience; } \\
\text { - More dangerous - opportunity for } \\
\text { misinformation; } \\
\text { - Dynamic; } \\
\text { - Also publish and subscribe. }\end{array}$ \\
\hline $\begin{array}{l}\text { Information } \\
\text { sharing }\end{array}$ & $\begin{array}{l}\text { - Fix deadlines (e.g. press, TV) and } \\
\text { schedules; } \\
\text { - Structured information sharing; } \\
\text { - Centralized process for information; } \\
\text { - Organization has control on the flow of } \\
\text { information, users can only read the } \\
\text { content. }\end{array}$ & $\begin{array}{l}\text { - } \text { - Unstructured information sharing; } \\
\text { - Decentralized process for information } \\
\text { distribution; } \\
\text { - Users may have the control on the flow of } \\
\text { information - they can also write and edit, } \\
\text { not only read the content. }\end{array}$ \\
\hline
\end{tabular}


Moreover, consumers' media usage habits also have been changed - they have more control over their media consumption through social media as they turned away from opportunities offered by traditional media. In the last few years use of social media has become to influence the people' decision making process -social media can enable organizations to change their consumers' decisions and behaviors. This phenomenon is due to the fact that social media has become more and more credible source of information.

Figure 1 New communications paradigm

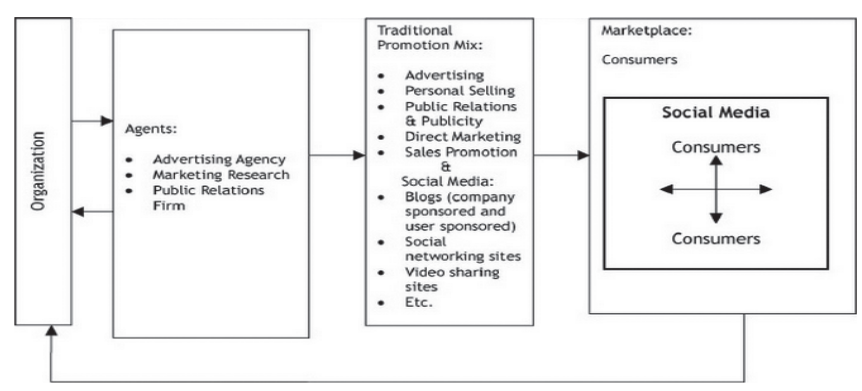

Source: Mangold and Faulds 2009

The study performed by SOCIAL MEDIA EXAMINER (2016) also confirms that social media marketing has become an important pillar for businesses. Major findings are listed below:

Video has become essential - a significant $60 \%$ of marketers use video in their marketing activity and $73 \%$ plan on increasing their video use. Moreover, live video is a hot topic - a significant $50 \%$ of marketers plan on using live video services such as Facebook Live and Periscope, and 50\% want to learn more aboutlive video;

Snapchat is on a growth trajectory - although only $5 \%$ of marketers are using Snapchat, $16 \%$ plan on increasing their Snapchat activities and $28 \%$ of marketers want to learn more about Snapchat;

The domination of Facebook is continuous - it is the most important social network for marketers. When asked to select their most important platform, $55 \%$ of marketers chose Facebook, followed by LinkedIn at 18\%. Plus, $67 \%$ of marketers plan on increasing their Facebook marketing activities;

Facebook and YouTube hold the top platforms for future plans - at least $63 \%$ of marketers plan on increasing their use of these particular social media sites;

Many marketers are unsure about their Facebook marketing - a significant $40 \%$ of marketers don't know if Facebook traffic has declined in the last 12 months and $35 \%$ aren't sure if their Facebook marketing is effective;

Facebook ads dominate - $86 \%$ of social marketers regularly use Facebook ads;

Tactics and engagement are top areas marketers want to master - at least $90 \%$ of marketers want to know the most effective social tactics and the bestways to engage their audience with social media.

According to the research about the Internet usage by the individuals in Hungary, National Media and Infocommunications Authority (NMHH) states that in 2016 (as in 2015), 95\% of the analyzed population (at least 16 years old Internet users who use the Internet weekly) visited social networking sites at least once a week during the previous half year of the research. Based on its research the domination of the two market leaders - Facebook and YouTube - is obvious in Hungary, thus the popularity of the other social media applications is very low. Facebook was visited by 5.1 million users weekly, followed by YouTube with 4.3 million users and the others with 2.9 million users. The most relevant and serious growth was reached by Instagram in 2016 while Pinterest has likely become to catch up. It is interesting fact - compared with the US - Twitter did not manage to reach the critical mass in Hungary which would be essential for a significant growth (NMHH, 2017).

Although it is obvious that use of different social media applications is continuously increasing in the European Union - as can be seen in Figure 2 - , only $36 \%$ of enterprises (for example restaurants) used these type of diverse marketing communication tools in 2017. Furthermore, it is noticeable that $26 \%$ of enterprises in the EU used only one of the four

Figure 2: Enterprises using social media in the European Union (\% of enterprises)

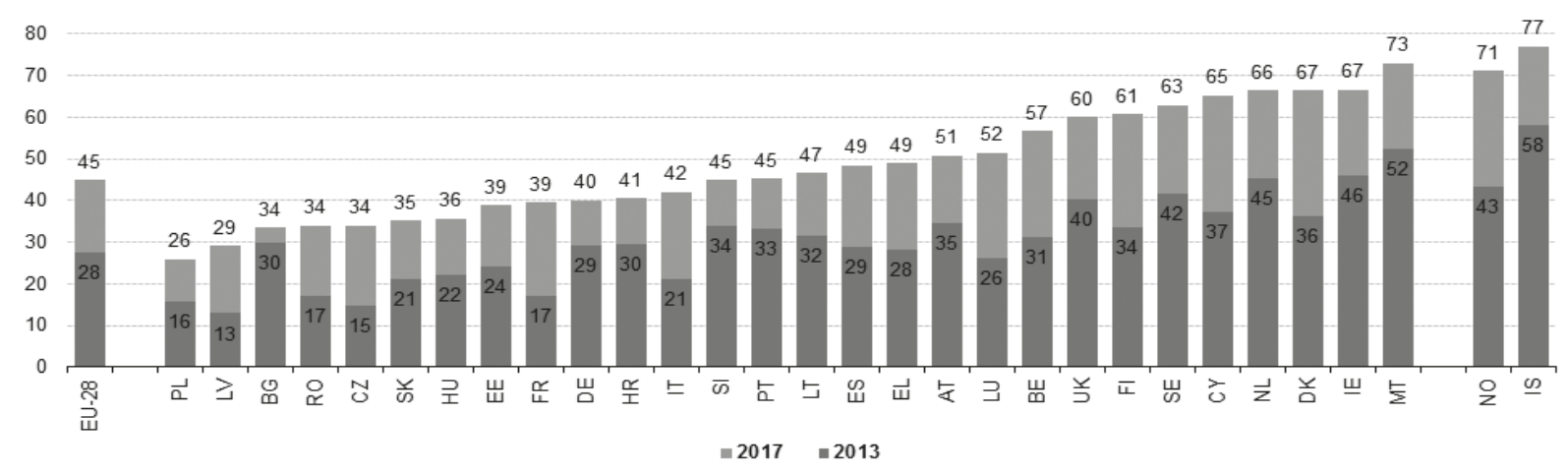

Only countries with data for both years

Source: Eurostat, 2017 
types of social media. Hence, there is a great market potential in social media usage especially in Hungary (EUROSTAT, 2017).

It is also important to distinguish the purposes for which enterprises were exploiting social media in 2017: it might be to reach its customers, business partners or other organizations; or it might be for communication inside the enterprise or for specific purposes such as to recruit employees. Based on the Eurostat Statistics (2017) Figure 3 demonstrates that $40 \%$ of EU enterprises used social media to develop the enterprise's image or market products. The second main reason for using social media (only $27 \%$ ) is to obtain or respond to customers' opinions, reviews or questions. As concerns communication inside the enterprise, $13 \%$ of enterprises reported to have used social media to exchange views, opinions or knowledge within the enterprise (EUROSTAT, 2017).

\section{GASTRONOMY AS A SCIENCE}

The importance of gastronomy as part of tourism is continuously increasing day-by-day. This fact is verified by the Committee on Culture and Education of the European Parliament who approved a motion for European Parliament Resolution on the European gastronomic heritage in 2014: cultural and educational aspects. "It recognizes the importance of food and gastronomy as artistic and cultural expression and fundamental pillars of family and social relationships" (CAVICCHI and CIAMPI STANCOVA 2016).

According to IVANOVIĆ et al. (2008) gastronomy is part of the experience economy. Recently, due to the strong competition and spread of mass tourism, the communication of hotels and restaurants is influenced not only by different marketing strategies such as STP (segmentation, targeting and positioning) marketing but also by those guests and partners who can add value to their businesses. Gastronomy is not easy to define, as can be seen from the huge number of definitions determined by the different Authors. A simple and easily manageable explanation of gastronomy is that it is concerned with the enjoyment of food and beverages. However, for the gourmet and gastronome, it essentially requires a broader definition: this is the enjoyment of good food and good beverage, in good company.

Based on the definition and classification of gastronomy written by IVANOVIĆ et al. (2008) the following types of gastronomy can be distinguished:

Practical gastronomy: contains the practice and study of the preparation, production and service of the different foods and beverages, from different countries around the world, i.e. the cuisines. If we mention practical gastronomy we also think about the techniques and standards involved in the conversion of raw produce into aesthetic, nationally, regionally and culturally specific edible products, complete dishes and menus (MORGAN, 2006). It is such an area where the chef and the food and beverage professional can be supremely active and creative.

Theoretical gastronomy: supports practical gastronomy with a process approach, focused on recipes, cookery books and other writing. It records various procedures and methods that must be carried out in order to maximize the productivity and success.

Technical gastronomy: it is more than knowledge of specifications for plant and machinery, and how they can effect productions and service. Technical gastronomy is a line between the small-scale operation and mass manufacture. It is also about the evaluation of convenience foods, new and evolutionary plant, newer production methods such as sous vide, and the skills and equipment required to place these into production and safely monitor performance of them over trial periods. Research and development technicians, development chefs and food scientists, operational specialists, consultant

Figure 3: Enterprises using social media, by purpose of use (\% of enterprises)

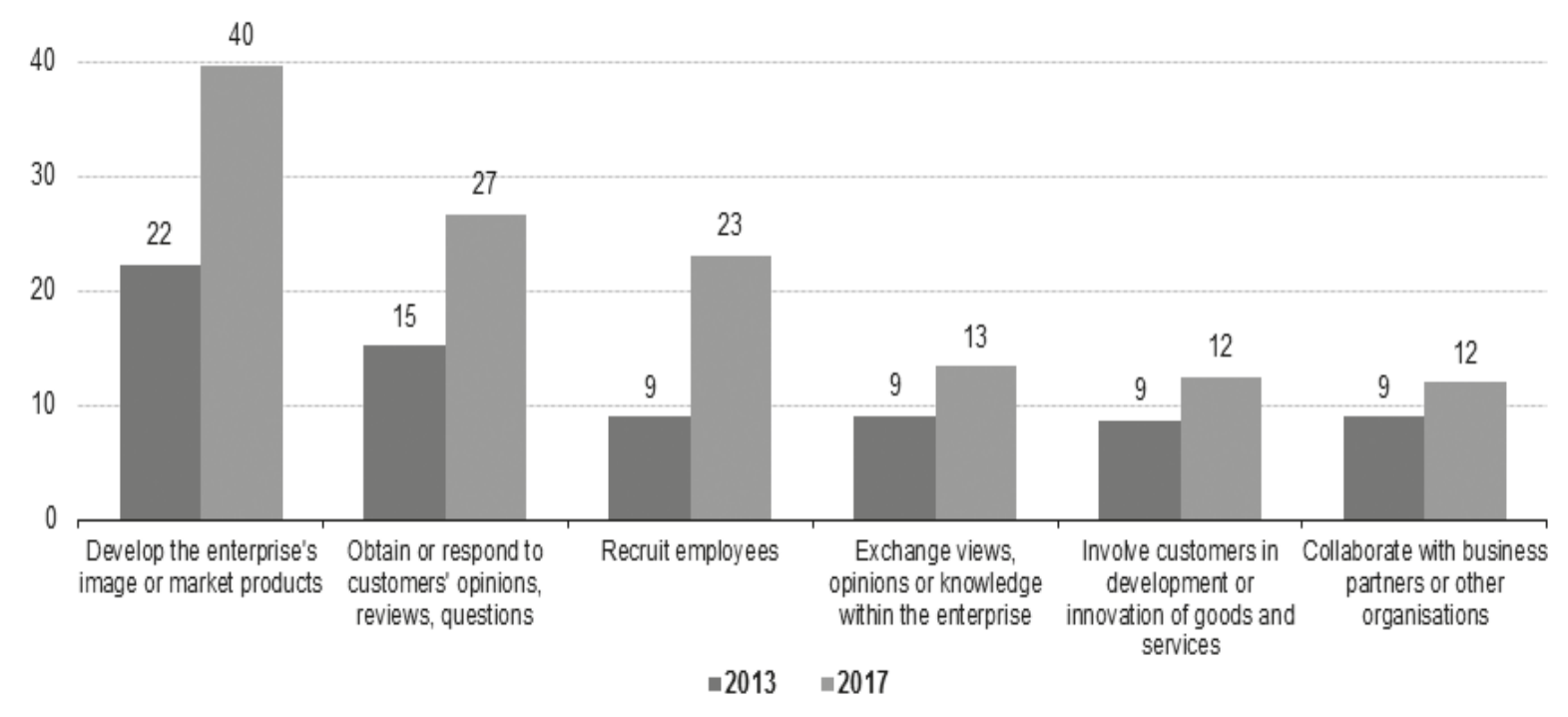

Source: Eurostat, 2017 
chefs and group chef executives work in this area.

Food gastronomy is dealing with food and beverages and also their genesis. Fundamentally, the role of wine, and other beverages, in relation to food is to harmonize, in order to maximize the enjoyment.

Gastronomy therefore provides a platform for a better understanding of how food and beverage resources are used in a particular situation. Through gastronomy it is possible to build a picture of the similarities of different approaches used in diverse countries and cultures. (IVANOVIĆ et al. 2008)

Gastro-tourism is a relatively new concept - it is a novel form of cultural tourism, which focuses on the values of local communities and blends the exploration of local and regional traditions, as well as the treasures of gastronomy (UNWTO, 2012). Due to the global recession Hungarian restaurants had to find new strategies for the new challenges in order to increase the number of guests and stay competitive - they have become to exploit the opportunities offered by the gastro-tourism. In Hungary, the restaurants sub-sector is the largest in terms of enterprise numbers, turnover and employment in the hospitality sector. Restaurants accounted for $49 \%$ of all hospitality sector turnover in 2010, and $54 \%$ of all employment. However, the circumstances of restaurants is relatively difficult in Hungary - due to the financial crisis local population became to decrease their expenses, and there was a radically decline in the rate and absolute number of local guests in the restaurants. For example a report written by AC Nielsen states that the highest rate of population who never goes to restaurant is in Hungary (17\%), and only $28 \%$ of the total population goes there at least once annually (compared with $68-78 \%$ in France) in the European Union (BARNÓTH, 2014). On the other hand, the development of gastro-tourism is not enough, restaurants sector should reach also the local people. The home and office food delivery business model have been identified as a key area of opportunity going forward, due to the development of IT and telecommunications capability - such as the different social media applications (ERNST\&YOUNG, 2013).

\section{RESEARCH HYPOTHESES}

In this part, we first would like to address the role of social media in Hungary regarding gastronomy industry and see what kind of restaurants are preferred by social media users. Moreover, we will discuss about the gender and focused group. In general, the following 3 hypotheses are presented:

H1: Social media have a huge impact on the guest's decision making processes regarding gastronomy industry in Hungary.

H2: Social media users are sensitive to prices while they are looking for their preferred restaurants in Hungary.

H3: There is a difference between genders in terms of social media in gastronomy industry in Hungary.

Research methodology

In the first step, we undertook a conceptual exploration of the relationship of social media and gastronomy industry by means of a systematic review of academic literature. In the second step, this research did quantitative analysis by considering the entire hypothesis based on the designed questionnaire by marketing experts work in a marketing consultant company. This company basically has ordinary registered marketing participants and the questionnaire was distributed among them.

In fact, we are looking for certain relationships and the differences among groups in this research. Therefore, "hypothesis testing" is the purpose of this study. Among different types of data-collection methods, we collected data from regular participants by conducting an "internet-based survey questionnaire" which participants were asked to answer the questionnaire which includes 37 different questions. Some of them are open questions and the rest of the them are designed using 4 Likert scale which determine importance with answers of the following type: very important, relatively important, less important, not important.

In addition, time horizon is "one-shot", because data are gathered just once from 20th of May till 10th of June. Moreover, none of the variables were manipulated, so the extent of researchers' interference is "minimal".

The collected data were analyzed using demographic analysis and descriptive analysis in order to test the hypotheses.

Data analysis and results

In order to reach our objectives, through the Epanel which was created by the online marketing consultant company as already mentioned. For this research, a total of 256 different users with different ids have participated in the survey.

Table 2 presents some of the demographic results such as gender, place of residence and age range.

Table 2 Demographic results

\begin{tabular}{|c|c|c|}
\hline \multicolumn{3}{|c|}{ Table 3. Demographic results } \\
\hline \multirow{4}{*}{ Gender } & & No. of participants \\
\hline & Men & 56 \\
\hline & Women & 200 \\
\hline & Total & 256 \\
\hline \multirow{5}{*}{$\begin{array}{l}\text { Place of } \\
\text { residence }\end{array}$} & Budapest & 100 \\
\hline & Country side & 38 \\
\hline & City & 92 \\
\hline & Town & 26 \\
\hline & Total & 256 \\
\hline \multirow{7}{*}{ Age range } & Under 20 & 8 \\
\hline & $21-30$ & 92 \\
\hline & $31-40$ & 64 \\
\hline & $41-50$ & 54 \\
\hline & $51-60$ & 25 \\
\hline & Above 61 & 13 \\
\hline & Total & 256 \\
\hline
\end{tabular}

Source: own edition (2017) 
As Table 2 shows, mostly women participated in this survey and the main reason was, this topic is more popular among the females according to the manager of the marketing consultant company.

\section{HYPOTHESIS 1:}

As already mentioned, the main objective was to study the role and impact of social media in Hungary regarding gastronomy industry. Out of the 37 questions 11 questions were included in the questionnaire to test this hypothesis. Descriptive analysis was done and as Figure 4 shows, just for $14 \%$ of participants highly preferred to refer social media in order to find a proper restaurant is important in Hungary.

Figure 4 Participants ratio's sensitiveness regarding using social media during decision making process

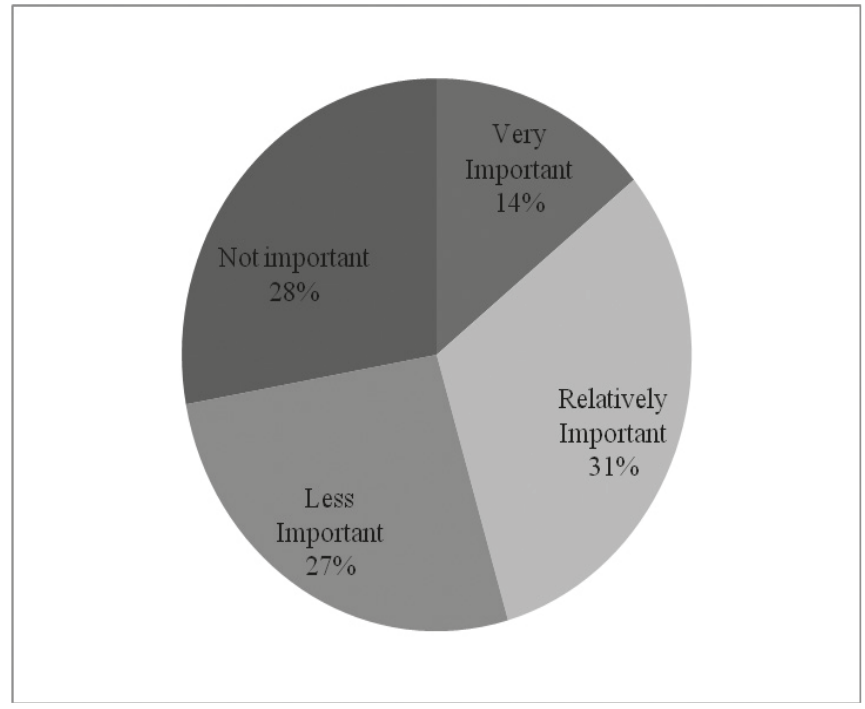

Source: own edition, 2017

Unlike our expectations, most of the participants didn't look for information when they are surfing on the net in order to find their preferred restaurants. Therefore, first hypothesis is rejected.

\section{HYPOTHESIS 2:}

One of the controversial questions which made our mind busy was what types of restaurants people prefer when they are looking for through different types of social media. In order to find the right answer, four questions based on their salary, how much they are willing to spend in an occasion, frequency of going to a restaurant and finally how they categorize different types of restaurants were asked. Table 3 illustrates how our Hungarian participants categorized restaurants based on expenses.
Table 3 Types of restaurant

\begin{tabular}{|c|c|c|c|}
\hline Cheap & Medium & High Class & Luxury \\
\hline $\begin{array}{c}\text { Less than 5000 } \\
\text { HUF }\end{array}$ & H000-10000 & $10000-15000$ & More than 15000 \\
Source: own edition (2017) & HUF \\
\hline \multicolumn{4}{|c}{ Souf } \\
\hline
\end{tabular}

As already mentioned, 55\% of respondents did not care of the information in social media about restaurants and gastronomy industry in Hungary. In order to avoid any kind of biases and for checking the second hypothesis, those answers were extracted which belong to people who care very or relatively important to the information in different types of social media. Results are shown in Figure 5 for those who care very important and in Figure 6 for those who care relatively important.

Figure 5 Preferred restaurants ratio based on those who care important to data in social media

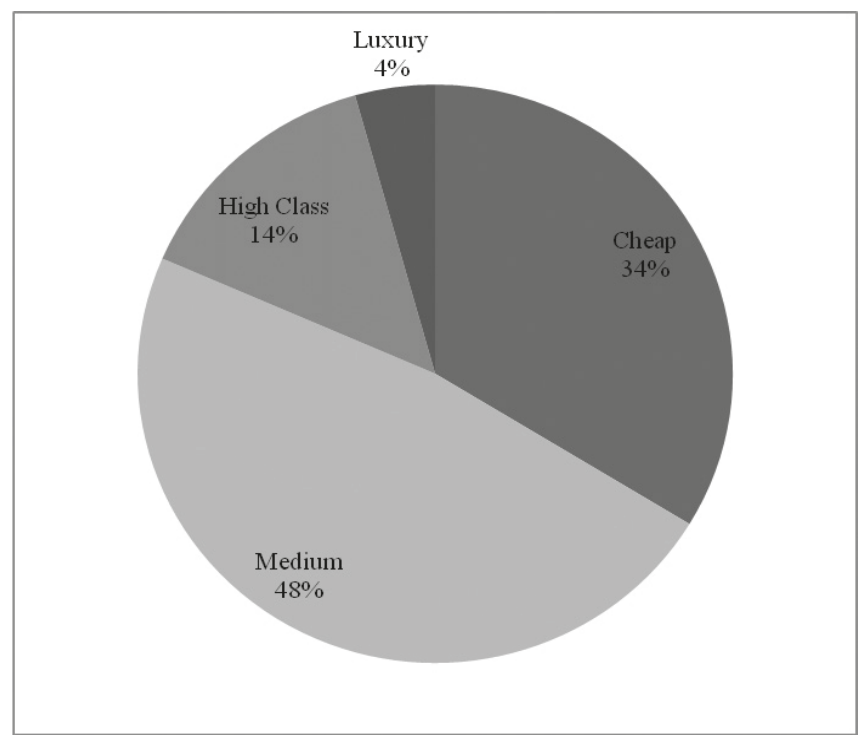

\section{Source: own edition (2017)}

Figure 6 Preferred restaurants ratio based on those who care relatively important to data in social media

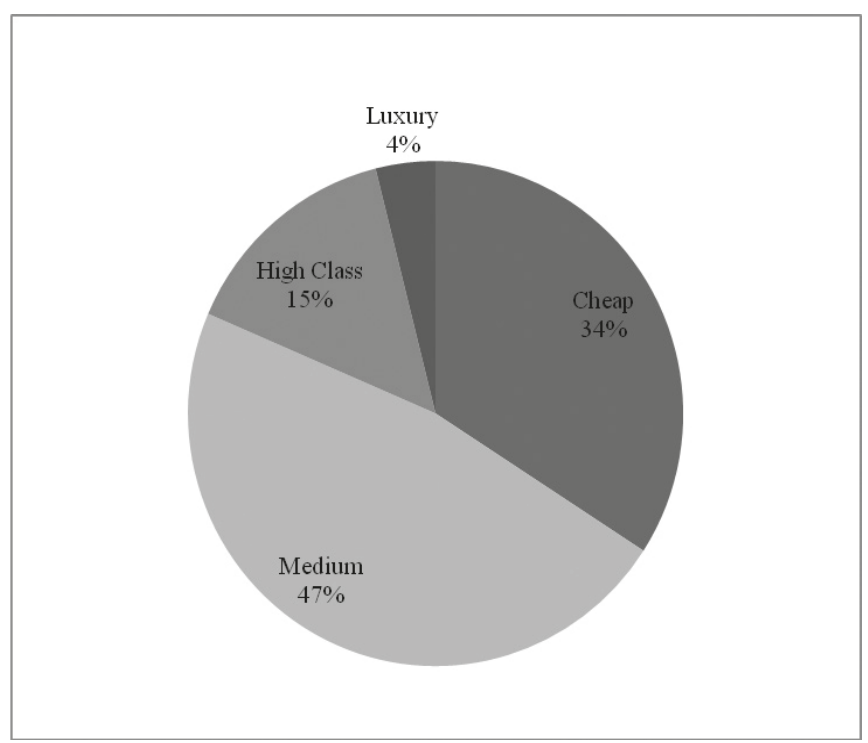

Source: own edition (2017) 
As Figure 5 and 6 show, those participants who are willing to find a proper restaurant through different types of social media, they prefer medium and cheap ranges ones. According to this result, second hypothesis is accepted.

\section{HYPOTHESIS 3:}

Which gender is willing to surf on the net more than the other in order to find a proper restaurant? For analyzing this hypothesis, just $45 \%$ of the respondents' answers were used again based on 5 different questions in the designed questionnaire. Those answers which belong to people who care and trust very or relatively important to the information in different types of social media. Figure 7 belongs to those who care very important and Figure 8 relates to respondents who care relatively important.

\section{Figure 7 Gender classification for those who care very important to} data in social media

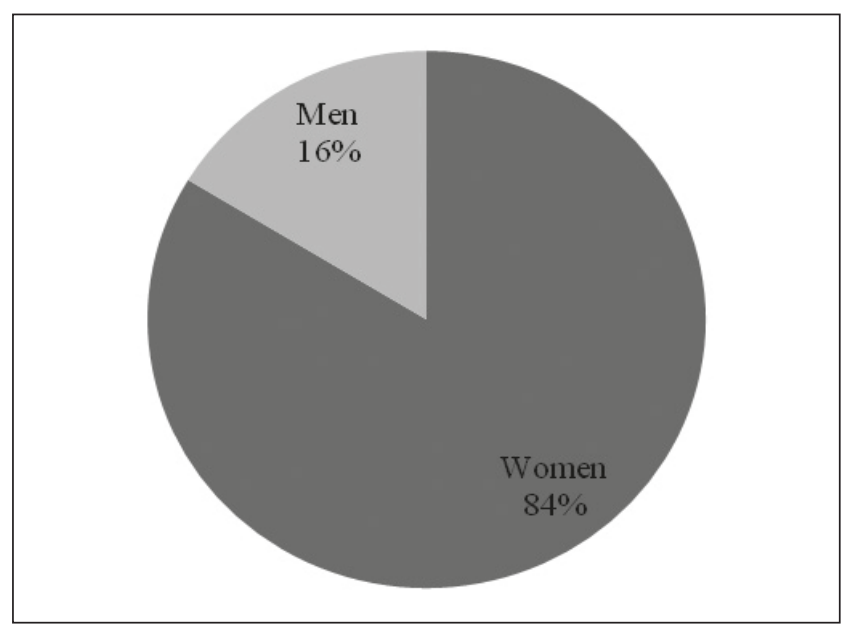

Source: own edition (2017)

Figure 8 Gender classification for those who care relatively important to data in social media

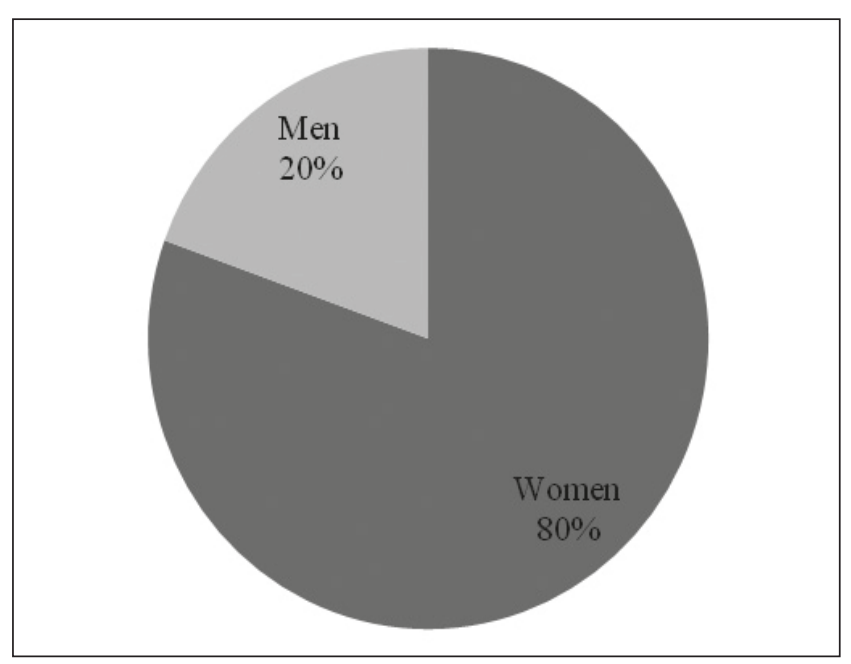

Source: own edition (2017)
As already mentioned in the literature, women are using social media more frequently than men. Based on the results from our survey, women are more sensitive to the information concerning gastronomy industry and they trust more than men to different types of social media. Consequently, third hypothesis is also accepted.

\section{CONCLUSION}

Despite the many threats and various weaknesses it possesses, there is no doubt, that social media usage is growing rapidly and it is gradually influencing our life and decisions. As gastronomy industry has several specialties, the use of social media is a relatively new challenge in this field. Based on the literature review it is essential to mention that there are no sophisticated and fully-developed methods of social media usage in gastronomy industry, however, based on the continuously increasing number of researches it is obvious that different actors are looking for new opportunities and ways to understand the changing needs and habits of consumers. The new challenges caused by global recession and innovations of information technologydemonstrate the need to use social media in different types of organizations for example in gastronomy industry - this IT tool is the most effective way for knowledge transfer in all sectors in the $21^{\text {st }}$ century. This study is intended to contribute to the application and necessity of social media in the special area of gastronomy industry and also the development of research methodology. Based on the survey the following conclusions were also listed:

It seems our participants who can be a sample of Hungarians don't care so much to the social media information about the gastronomy industry, specially choosing a restaurant in Hungary and it's totally unlike the results which done by researchers in western countries.

The social media information are referred, when people are looking for a restaurant in the range of 5000-10000 HUF.

Women are willing to get information through the social media in the scope of gastronomy more than men.

As a recommendation, restaurants should focus of the group of women who can be reached effectively through the different social media applications. Ranking of the restaurants was also recommended in order to advertise and communicate effectively through social media applications:

Cheap restaurants. Less than 5000 HUF

In the range of $5000-10000 \mathrm{HUF}$

In the range of $10000-15000 \mathrm{HUF}$

Luxury restaurants: More than 15000 HUF

Results and implications of analysis need further empirical confirmation, hence a representative research is planned in future work, which examines deeply the consumers' restaurant choosing habits and also the social media usage of different types of restaurants in Hungary. 


\section{REFERENCES}

Barnóth, K. (2014): A Miskolc belvárosi hagyományos éttermi vendéglátás és a vele kapcsolatos marketingtevékenység elemzése, Miskolci Egyetem: Miskolc

Bolton, R.N., Parasuraman, A., Hoefnagels, A., Kabadayi, S., Gruber, T., Loureiro, Y.K., Migchels, N. and Solnet, D. (2013): Understanding Gen Y and their use of social media: a review and research agenda', Journal of Service Management, 24(3): 245-267.

Boulos M.N.K. and Wheelert, S., (2007): Blackwell Publishing Ltd The emerging Web 2.0 social software: an enabling suite of sociable technologies in health and health care education', Health Information and Libraries Journal, 24: 2-23

Buhalis, D., and Law, R. (2008): Progress in information technology and tourism management: 20 years on and 10 years after the Internet - The state of eTourism research, Tourism Management, 29(4): 609-623.

Cavicchi, A. and Ciampi Stancova, K. (2016): Food and gastronomy as elements of regional innovation strategies. European Commission, Joint Research Centre, Institute for Prospective Technological Studies, Spain.

Ernst\&Young (2013): The hospitality sector in Europe, Available at: http://www.ey.com/Publication/vwLUAssets/The_Hospitality_Sector_in_Europe/\$FILE/EY_The_Hospitality_Sector_in_Europe.pdf Approached October 6, 2017

Eurostat (2017): Social media - statistics on the use by enterprises, Available at: http://ec.europa.eu/eurostat/statistics-explained/ index.php/Social media - statistics on the use by enterprises Approached February 4, $\overline{2} \overline{0} 18$

Evans, R., (2014): The use of web 2.0 technologies in business, Lecture note, Cranfield University, Cranfield, United Kingdom

Kaplan, A.M. and Haenlein, M. (2010): Users of the world, unite! The challenges and opportunities of Social Media', Business Horizons, 53(1): 59-68

Kirtis, A.K. and Karahan, F. (2011): To Be or Not to Be in Social Media Arena as the Most CostEfficient Marketing Strategy after the Global Recession', 7th International Strategic Management Conference, Procedia Social and Behavioral Sciences, pp. 260-268.

Kot, S., Ferencová, M. and Kakalejcík, L. (2016): Using of Selected Social Media in Slovakia and Poland - Comparative Study'. Mediterranean Journal of Social Sciences, 7(3): 113-120.

Lovelock and Wirtz (2007): Services Marketing: People, Technology, Strategy, $6^{\text {th }}$ edition, Pearson: New Jersey

Mangold, W.G. and Faulds, D.J. (2009): Social media: The new hybrid element of the promotion mix, Business Horizons, 52(4): 357-365
Morgan, J.L. (2006): Culinary creation an introduction to foodservice and world cuisine, $1^{\text {st }}$ edition, Taylor\&Francis Ltd.: New York

Neuhofer, B., Buhalis, D., and Ladkin, A. (2013): Experiences, co-creation and technology: A conceptual approach to enhance tourism experiences', Tourism and global change: On the edge of something big. CAUTHE 2013 Conference Proceedings, 546-555.

NMHH (2017): Internet usage by individuals - Online survey 2016, Available at: http://nmhh.hu/dokumentum/187704/lakossagi_internethasznalat_2016.pdf Approached June 10, 2017

O'Reilly, T. (2005): What is web 2.0. Available at: http://www. oreilly.com/pub/a/web2/archive/what-is-web-20.html Approached June 20, 2015

Rodríguez, O.S., Chaisatit, N. and Hernández, A.D.C.B (2015): Marketing through Social Networks in Touristic and Gastronomy Industry in Manzanillo, Colima, México', Global Review of Research in Tourism, Hospitality and Leisure Management (GRRTHLM) An Online International Research Journal, 1(1): 268-274.

Ryan, D. (2014): Understanding digital marketing: marketing strategies for engaging the digital generation, 3rd edn. London: Kogan Page

So, K.F., King, C. and Sparks, B. (2012): Consumer engagement with tourism brands: scale development and validation', Journal of Hospitality and Tourism Research, 38(3): 304-329.

Socialbakers (2017): Free Social Media Statistics, Available at: https://www.socialbakers.com/statistics/ Approached January 27, 2017

Social Media Examiner (2016): 2016 Social Media Marketing Industry Report, Available at: https://www.socialmediaexaminer. com/wp-content/uploads/2016/05/SocialMediaMarketingIndustryReport2016.pdf Approached January 27, 2017

Solis, B. (2015): The Conversation Prism, Available at: https:// conversationprism.com/ Approached June 20, 2015

Statista (2018): Number of social media users worldwide 20102021. Available at: https://www.statista.com/statistics/278414/ number-of-worldwide-social-network-users/ Approached February 5,2018

United Nations World Tourism Organisation (UNWTO) (2012): Global report on food tourism. UNWTO: Madrid.

Vivek, S.D., Beatty, S.E. and Morgan, R.M. (2012): Consumer engagement: exploring consumer relationships beyond purchase', Journal of Marketing Theory and Practice, 20(2): 122-146.

Živković, R., Gajić, J. and Brdar, I. (2014): The impact of social media on tourism, Impact of Internet on business activities in Serbia and worldwide - E-business in tourism and hospitality industry, Proceedings, pp. 758-761. 
